\title{
POSTOPERATIVE USE OF APROTININ IN CARDIAC OPERATIONS: AN ALTERNATIVE TO ITS PROPHYLACTIC USE
}

Sertaç Çiçek, MD*

Ufuk Demirkiliç, MD

Ertugrul Özal, MD

Erkan Kuralay, MD

Hakan Bingol, MD

Harun Tatar, MD

Ömer Y. Özturk, MD
Background: Aprotinin reduces blood loss after cardiopulmonary bypass. Although there can be little doubt about the efficacy of aprotinin, its safety has been questioned recently and is still under investigation. Because of the potential for complications and the high cost, a selective strategy limiting drug delivery to patients with established postoperative bleeding will be more reasonable. Methods: In a prospective, randomized, double-blind trial we studied the effect of postoperative low-dose ( 2 million kallikrein inactivator units) aprotinin on blood loss and transfusion requirements in patients undergoing cardiopulmonary bypass. Fifty-seven patients were randomly assigned to two groups: aprotinin or placebo. Results: The two groups were comparable in all demographic and surgical variables. Postoperative chest tube drainage was significantly less in the aprotinin group than in the placebo group $(410 \mathrm{ml}$ vs $696 \mathrm{ml}, p<0.01)$. The use of homologous blood products was significantly less in the aprotinin group than in the placebo group $(0.4 \pm 0.5$ unit vs $1.7 \pm 0.9$ unit for packed red blood cells and $0.8 \pm 1.3$ unit vs $2.3 \pm 1.6$ unit for fresh frozen plasma) Conclusions: Our results suggest that postoperative aprotinin reduces blood loss and transfusion requirements and provides the opportunity to restrict its use selectively to patients with excessive postoperative bleeding. (J Thorac Cardiovasc Surg 1996;112:1462-7)

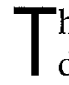
he serine proteinase inhibitor aprotinin has been demonstrated to decrease postoperative bleeding and transfusion requirements in patients undergoing cardiac operations with cardiopulmonary bypass (CPB). ${ }^{1}$ Since the first description of high-dose aprotinin for prophylaxis against excessive postoperative bleeding, numerous studies with different dosage protocols have been published that confirmed the efficacy of the drug. ${ }^{2-4}$ It has been suggested that aprotinin should be given before and during CPB to produce a constant plasma concentration to prevent fibrinolysis and to protect platelet function.

From Department of Cardiovascular Surgery, GATA Gülhane School of Medicine, Ankara, Turkey.

Received for publication March 19, 1996; revisions requested April 22, 1996; revisions received May 7, 1996; accepted for publication May 14, 1996.

Address for reprints: Sertaç Çiçek, MD, Section of Cardiovascular Surgery, Mayo Clinic, 200 First St. SW, Rochester, MN 55905 .

*Present address: Section of Cardiovascular Surgery, Mayo Clinic, Rochester, MN 55905.

Copyright (C) 1996 by Mosby-Year Book, Inc.

$0022-5223 / 96 \$ 5.00+0 \quad \mathbf{1 2 / 1 / 7 4 9 0 1}$
Although initial clinical reports suggested aprotinin to be safe with few side effects, evidence has recently appeared that questions its overall safety for prophylactic systemic therapy. Adverse effects on coronary artery bypass graft patency, renal impairment, anaphylactic reactions during subsequent exposures, and disseminated intravascular coagulation after profound hypothermia have been attributed to the systemic use of aprotinin. ${ }^{5-7}$ The cost of a high-dose aprotinin regimen is equivalent to the cost of about 8 to 10 units of blood. ${ }^{8}$ The high cost of aprotinin restricts routine prophylactic use in many centers, especially in the United States, because of potential limitations in reimbursement to all health care providers. ${ }^{9}$

Excessive bleeding after cardiac operations is a major concern for cardiac surgical teams. It has been reported in $5 \%$ to $25 \%$ of patients undergoing CPB. ${ }^{10}$ This figure becomes more important in view of the increasing number of reoperations and emergency surgical procedures during which patients are still under the effect of antiplatelet or antifibrinolytic agents. However, only $3 \%$ to $5 \%$ of all patients undergoing cardiac operations require reoperation for bleeding. ${ }^{11}$ This supports our contention that the 
Table I. Operative procedures performed

\begin{tabular}{lcc} 
Operations & $\begin{array}{c}\text { Aprotinin group } \\
(n=29)\end{array}$ & $\begin{array}{c}\text { Placebo group } \\
(n=28)\end{array}$ \\
\hline CABG & 19 & 17 \\
AVR or MVR & 5 & 8 \\
DVR & 4 & 3 \\
CABG-AVR & 1 & - \\
\hline
\end{tabular}

$C A B G$, Coronary artery bypass grafting; $A V R$, aortic valve replacement; $M V R$, mitral valve replacement; $D V R$, double valve replacement (AVR and MVR)

majority of patients who are treated with aprotinin are unnecessarily exposed to side effects of the drug. It would be prudent to apply aprotinin on a more selective basis to avoid adverse reactions and unnecessary prophylactic use. One effective strategy to achieve these goals would be to restrict the use of aprotinin exclusively to patients with established postoperative bleeding. Angelini and colleagues ${ }^{12}$ reported six cases in which aprotinin postoperatively reduced bleeding that failed to respond to conventional treatment. More recently, Kallis and associates ${ }^{13}$ demonstrated that postoperative use of aprotinin in patients with established bleeding reduced blood loss. However, further studies are warranted on this topic.

This clinical randomized double-blind study was conducted to investigate the effect of aprotinin given postoperatively on blood loss and transfusion requirements in patients undergoing cardiac operations.

\section{Patients and methods}

A randomized, double-blind, placebo-controlled study was carried out to compare the efficacy of postoperative aprotinin and placebo to decrease bleeding and transfusion requirements on patients undergoing cardiac operations with CPB. Informed consent was obtained from all patients. Patients who had previous exposure to aprotinin or who had received systemic or topical aprotinin during the operation were excluded from the study. Fifty-seven patients were included in the study and were randomized to receive aprotinin or placebo by means of the table of random numbers.

Aprotinin group. Patients in the aprotinin group received a bolus of $2 \times 10^{6}$ kallikrein inhibiting units (KIU) of aprotinin $(280 \mathrm{mg}$ ) (Trasylol; Bayer AG, Leverkusen, Germany) infused over 15 minutes when they arrived in the intensive care unit (ICU).

Placebo group. Patients in the placebo group received an equal volume of normal saline solution at all corresponding times.

The operative procedures performed are defined in Table I. All patients were operated on and cared for by the same team.
Table II. Patient characteristics*

\begin{tabular}{lcc}
\hline \multicolumn{1}{c}{ Variable } & Aprotinin & Placebo \\
\hline$n$ & 29 & 28 \\
Age (yr) & $51.6 \pm 15.4$ & $48.2 \pm 14.2$ \\
Male/female & $21 / 8$ & $19 / 9$ \\
Preop. aspirin $(n)$ & 14 & 13 \\
CPB time (min) & $97.5 \pm 45.6$ & $78.4 \pm 25.5$ \\
No. of grafts & $2.8 \pm 0.7$ & $2.6 \pm 0.7$ \\
No. of ITAs & $0.9 \pm 0.2$ & $0.7 \pm 0.4$ \\
\hline
\end{tabular}

${ }^{*}$ Values are mean \pm standard deviation. No significant differences were observed in patient characteristics.

The anesthetic management and conduct of $\mathrm{CPB}$ were standardized. The extracorporeal circuit consisted of a hollow-fiber membrane oxygenator (Terumo Copiox E, Terumo Co., Tokyo, Japan). Polyvinyl chloride tubing was used throughout the circuit except for the roller pump tubing, which was silicone rubber. Before CPB patients were given $300 \mathrm{U}$ bovine lung heparin per kilogram of body weight; whenever the activated clotting time was shorter than 480 seconds, additional doses of heparin were given.

Mild to moderate hypothermia, cold crystalloid cardioplegic solution (Plegisol, Abbott Laboratories, North Chicago, IIl.) for induction of cardioplegia, and cold blood cardioplegic solution (infused every 20 minutes) for maintenance were used for myocardial protection. Before unclamping the aorta, we administered warm blood cardioplegic solution $\left(500 \mathrm{ml}\right.$ at $\left.37^{\circ} \mathrm{C}\right)$. The cardioplegic solution (either crystalloid or blood cardioplegic solution) was returned to the circuit. Left internal thoracic artery grafts were used routinely in patients undergoing coronary artery bypass grafting. The saphenous vein was harvested as needed. During systemic heparinization, blood was routinely returned to the pump-oxygenator and reinfused. Finally, all blood remaining in the venous tubing and in the oxygenator after $\mathrm{CPB}$ was collected and reinfused when necessary, during the operation or in the ICU. At the end of CPB, the heparin effect was reversed with protamine sulfate at a 1:1 ratio.

Hemoglobin concentration, hematocrit value, platelet count, prothrombin time, activated partial thromboplastin time, and fibrinogen levels were measured in all patients before the operation and when they arrived at the ICU. The shed mediastinal blood was collected in a commercially available volumetric collection system, and the amount was measured every half hour for the first day and hourly thereafter. The mediastinal and thoracic drains were removed when the total drainage was less than 100 $\mathrm{ml}$ over the previous 8 hours.

Homologous packed red cells were administered only when the hematocrit value fell to less than $24 \%$. Patients received fresh frozen plasma when excessive blood loss was accompanied by a prolonged $(>1.5$ times normal values) prothrombin time. Additional protamine was administered if the activated clotting time/control ratio was greater than 1.5. Platelet transfusions were not used. Shed blood was not autotransfused in any of the patients during this study. Reoperation for bleeding was undertaken if the 


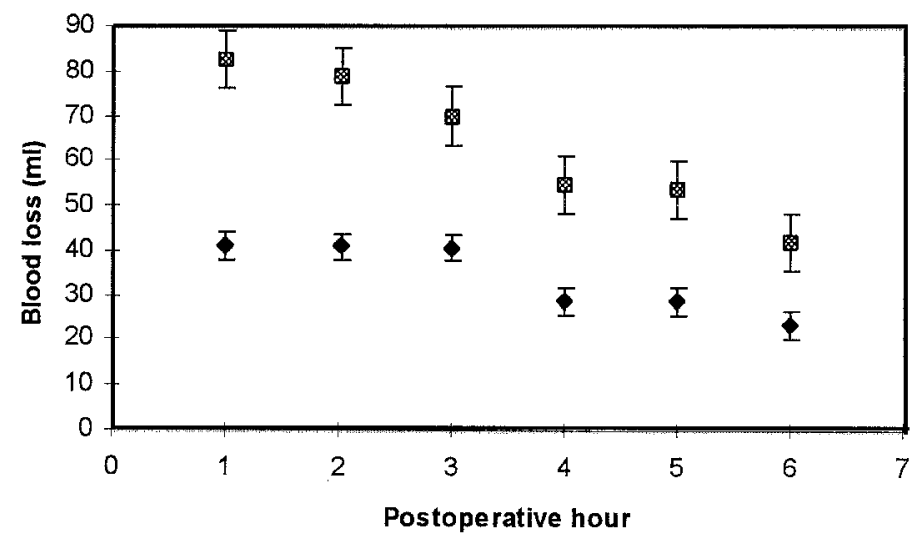

\section{Cumulative blood loss}

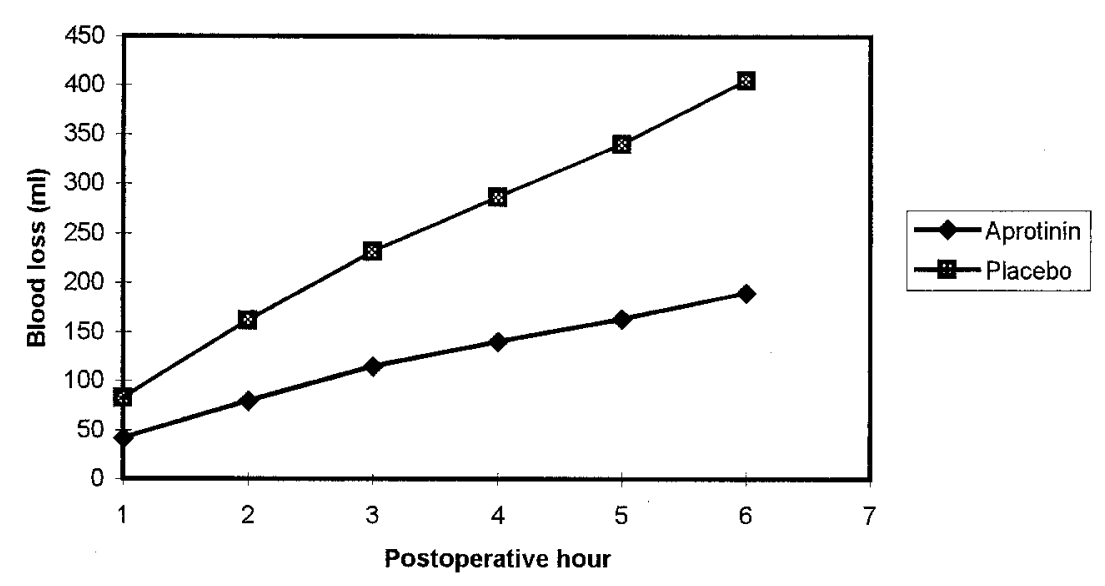

Fig. 1. A, Hourly blood loss for the first 6 hours after the initiation of aprotinin or placebo. Values are shown as mean \pm standard error of the mean. B, Cumulative blood loss in the first 6 hours.

blood loss exceeded $500 \mathrm{ml}$ for two consecutive hours without signs of decreasing despite appropriate therapy.

CPB time, total operation time, amount of total chest tube drainage, prevalence of reoperation for bleeding, cause of bleeding, and need for donor blood transfusion or fresh frozen plasma were recorded for all patients. The course of the blood hemoglobin content during hospitalization was analyzed in each patient.

Sample size was calculated by an expected difference in blood loss between groups of $250 \mathrm{ml}$, standard deviation of $250 \mathrm{ml}, \alpha=0.05, \beta=0.05$, with $n=28$ for each of the groups. All results are expressed as the mean values \pm standard deviation. Statistical comparisons were made by means of the Student's $t$ test. A $p$ value less than 0.05 was considered to be statistically significant. Statistical analyses were made with the use of the Primer of Biostatistics: The Program Version 3.02 (McGraw-Hill, Inc., New York, N.Y.) statistical software package.

\section{Results}

No differences were found between the aprotinin and placebo groups in patient age, sex, CPB time, and duration of operation. Fourteen patients in the aprotinin group and 13 in the placebo group had taken aspirin up until 7 days before the operation. Also, the number of bypass grafts and the number of 
Table III. Total transfusion requirement

\begin{tabular}{cccc}
\hline Variable & Aprotinin & Placebo & p Value \\
\hline $\begin{array}{c}\text { Packed RBC } \\
\text { (units per patient) }\end{array}$ & $0.45 \pm 0.50$ & $1.70 \pm 0.9$ & $<0.01$ \\
FFP & $0.80 \pm 1.36$ & $2.35 \pm 1.6$ & $<0.01$ \\
$\begin{array}{c}\text { (units per patient) } \\
\text { Patients receiving } \\
\text { transfusions (\%) }\end{array}$ & 37 & 64 & $<0.01$ \\
\hline
\end{tabular}

Values are mean \pm standard deviation.

internal thoracic arteries used per patient in patients undergoing coronary artery bypass graft operations were not statistically different between the groups (Table II). The types of operative procedures performed were comparable for the two groups. Except for one operation in the aprotinin group, these procedures were initial operations. There were also no significant differences between the groups in postoperative hemodynamics, duration of stay in the ICU, and postoperative hospital stay (data not shown). One patient in the aprotinin group was reoperated on for excessive bleeding. A sternal bleeding site was identified. There were no instances of renal impairment, perioperative myocardial infarction, or allergic reactions to aprotinin.

Fig. 1 shows the course of blood loss after commencement of aprotinin therapy. Postoperative blood loss at 1 hour was $82.5 \pm 60.7 \mathrm{ml}$ in the placebo group and was significantly lower in the aprotinin group $(40.7 \pm 51.5 \mathrm{ml})$. The trend in the reduction of blood loss continued in the aprotinin group throughout the first 6 hours and thereafter. Significantly less postoperative chest tube drainage was noted in the aprotinin group (including one patient who required reentry for surgical bleeding) than in the placebo group at the first 24-hour measurement $(410.5 \pm 174.8 \mathrm{ml}$ vs $696.2 \pm 247.7 \mathrm{ml}, p<0.01)$ and at the removal of chest tubes $(436.8 \pm 188.2 \mathrm{ml}$ vs $852.5 \pm 336.9 \mathrm{ml}$, $p<0.01$ ). The $95 \%$ confidence interval for difference in total blood loss was 271.4 to $559.8 \mathrm{ml}$.

The use of banked donor blood products during the operation was not significantly different between the groups. Hemoglobin values were similar in the two groups on arrival in the ICU, allowing a direct comparison between groups with regard to postoperative use of blood products. However, the transfusion requirement was significantly lower in the aprotinin group than in the placebo group (Table III). Only 37\% of aprotinin-treated patients required donor blood or blood products
Table IV. Hematologic values and coagulation tests

\begin{tabular}{lrr}
\hline & Aprotinin & Placebo \\
\hline Hemoglobin $(\mathrm{gm} / \mathrm{dl})$ & & \\
$\quad$ Preoperative & $13.2 \pm 1.1$ & $12.5 \pm 1.4$ \\
$\quad$ Postoperative & $8.9 \pm 1.1$ & $8.6 \pm 1.2$ \\
Platelets $\left(10^{9} / \mathrm{L}\right)$ & & \\
$\quad$ Preoperative & $287.2 \pm 84.9$ & $244.8 \pm 88.6$ \\
$\quad$ Postoperative & $136.2 \pm 50.9$ & $138.0 \pm 60.6$ \\
Fibrinogen (mg/d) & & \\
$\quad$ Preoperative & $424.0 \pm 92.8$ & $374.1 \pm 140.3$ \\
$\quad$ Postoperative & $312.3 \pm 72.8$ & $290.9 \pm 84.7$ \\
Prothrombin time (sec) & & \\
$\quad$ Preoperative & $13.2 \pm 0.5$ & $13.3 \pm 1.2$ \\
$\quad$ Postoperative & $13.3 \pm 0.8$ & $13.7 \pm 1.0$ \\
Partial thromboplastin time (sec) & & \\
$\quad$ Preoperative & $36.8 \pm 4.2$ & $35.3 \pm 3.2$ \\
$\quad$ Postoperative & $38.8 \pm 2.9$ & $39.5 \pm 2.2$ \\
\hline
\end{tabular}

"Values are mean \pm standard deviation. No significant differences were observed.

in comparison with $64 \%$ of those in the placebo group.

There were no statistically significant differences between the two groups with regard to platelet count, prothrombin time, activated partial thromboplastin time, and fibrinogen level before and early after the operation when patients arrived in the ICU (Table IV).

\section{Discussion}

Of all the drugs used to minimize postoperative bleeding, aprotinin has been the most successful. No other blood conservation agent has a comparable efficacy. ${ }^{9,14}$ However, a consensus has not been reached concerning patient selection and dosage regimen. Numerous reports have shown the benefits of both high-dose and low-dose regimens. Because of the potential for complications and the high cost of aprotinin, it is logical to use aprotinin on a more selective basis, that is, in patients with established postoperative bleeding.

This study demonstrated that postoperative blood loss and transfusion requirements were significantly lower in the aprotinin group than in the placebo group. The satisfactory reduction in postoperative blood loss in the aprotinin group prompted us to analyze the results of blood loss in a smaller subgroup of patients undergoing coronary artery bypass who continued to take aspirin until 1 week before the operation. Aprotinin treatment in these patients significantly decreased the postoperative blood loss. The mean blood loss in the aprotinin group was $460.7 \pm 174.7 \mathrm{ml}$ and in the placebo group, $960.7 \pm$ 
$305.2 \mathrm{ml} ;(p<0.01)$. In the present study we used the low-dose regimen ( 2 million KIU) because low-dose aprotinin is sufficient to obtain the required antiplasmin effect and to preserve glycoprotein Ib receptors. ${ }^{15,16}$ The reduction of postoperative blood loss, to our surprise, is comparable with that in other studies in which aprotinin was applied prophylactically. ${ }^{1,2}$ The most effective time to administer aprotinin during cardiac operations is still unknown. It has been universally recommended and accepted that aprotinin should be given before CPB and throughout the surgical procedure to be effective. ${ }^{17,18}$ Gram and colleagues ${ }^{19}$ suggested that significant amounts of tissue-type plasminogen activator are incorporated into fibrin generated after neutralization of heparin and thereby may cause the degradation of cross-linked fibrin until at least 24 hours after the operation, although tissue-type plasminogen activator has returned to baseline levels much earlier. Valen and associates ${ }^{20}$ also reported that increased fibrinolytic activity persists after CPB. The presence of fibrin or fibrin monomers stimulates fibrinolytic activity 100 -fold. ${ }^{21}$ This increased activity creates a positive feedback cascade and increases the risk of postoperative bleeding. Aprotinin may influence hyperfibrinolysis in the early postoperative period. However, quantification of plasmin levels is essential to detect the postoperative fibrinolytic state and aprotinin effect.

Kallis and associates ${ }^{13}$ have recently demonstrated the efficacy of aprotinin on hemostasis when used postoperatively on patients who bled significantly. The tissue plasminogen activator antigen decreased and fibrinogen level increased in the aprotinin group. Aprotinin also increased the platelet surface expression of glycoprotein $\mathrm{Ib}$ ( $36 \%$ vs $5 \%, p<0.01)$ and maintained the platelet von Willebrand factor activity. They suggested that aprotinin, by inhibiting excessive fibrinolysis and reducing plasmin levels, allows replenishment of the platelet surface glycoprotein Ib receptors from intraplatelet pools. Michelson and Barnard ${ }^{22}$ also have shown that platelets recover from plasmin as soon as it is neutralized by redistribution of the platelet glycoprotein Ib receptor. On the basis of current information, one could expect that postoperative aprotinin would restore platelet function through its antiplasmin effect.

The intact endothelium is involved in the regulation of hemostasis and thrombosis. It is known that endothelial dysfunction occurs systemically during CPB. ${ }^{23}$ Aprotinin has been shown to inactivate protein $\mathrm{C}$, which is the major regulatory protein of thrombus formation. ${ }^{24}$ Besides controlling the thrombin formation, protein $\mathrm{C}$ promotes fibrinolysis by inactivating the plasminogen activator inhibitors. ${ }^{25}$ The time course of endothelial dysfunction has not been established. Endothelial dysfunction of sublethal and long-lasting character may occur even without morphologic changes ${ }^{23}$ and cause leakage of tissue-type plasminogen activator stores after CPB, resulting in a hyperfibrinolytic state. Postoperative aprotinin may also exert an antifibrinolytic action by modulating endothelial cell function. However, the mechanism of this complex interaction requires more comprehensive investigations.

\section{Conclusions}

1. Aprotinin is effective even if administered after activation of the hemostatic system, with a consequent significant reduction in blood loss and transfusion requirements.

2. Efficacy of postoperative infusion also provides the opportunity to minimize the overzealous use of prophylactic aprotinin and restrict its use selectively to patients with established postoperative bleeding.

\section{REFERENCES}

1. Bidstrup BP, Royston D, Taylor KM. Reduction in blood loss and blood use after cardiopulmonary bypass with high dose aprotinin (Trasylol). J Thorac Cardiovasc Surg 1989;97:36472.

2. Blauhut B, Gross C, Necek S, Doran JE, Spath P, Lundsgaardhansen P. Effect of high-dose aprotinin on blood loss, platelet function, fibrinolysis, complement and renal function after cardiopulmonary bypass. J Thorac Cardiovasc Surg 1991;101:958-67.

3. Murkin JM, Lux J, Shannon NA, et al. Aprotinin significantly decreases bleeding and transfusion requirements in patients receiving aspirin and undergoing cardiac operations. J Thorac Cardiovasc Surg 1994;107:554-61.

4. Kawasuji M, Ueyama K, Sakakibara N, et al. Effect of low-dose aprotinin on coagulation and fibrinolysis in cardiopulmonary bypass. Ann Thorac Surg 1993;55:1205-9.

5. Cosgrove DM, Heric B, Lytle BW, et al. Aprotinin therapy for reoperative myocardial revascularization: a placebo-controlled study. Ann Thorac Surg 1992;54:1031-8.

6. Sundt T, Saffitz JE, Stahl DJ, Waring TH, Kouchoukos NT. Renal dysfunction and intravascular coagulation after use of aprotinin in thoracic aortic operations employing circulatory arrest. Ann Thorac Surg 1993;55:1418-24.

7. Westaby S, Forni A, Dunning J, et al. Aprotinin and bleeding in profoundly hypothermic perfusion. Eur J Cardiothorac Surg 1994;8:82-6.

8. Ferraris VA, Ferraris SP. Limiting excessive postoperative blood transfusion after cardiac procedures. Tex Heart Inst $\mathbf{J}$ 1995;22:216-30.

9. Fremes SE, Wong BI, Lee E, et al. Metaanalysis of prophy- 
lactic drug treatment in the prevention of postoperative bleeding. Ann Thorac Surg 1994;58:1580-8.

10. Bick RL. Hemostasis defects associated with cardiac surgery, prosthetic devices and extracorporeal circuits. Semin Thromb Hemost 1989;15:173-7.

11. Arom KV, Emery RW. Decreased postoperative drainage with addition of $\epsilon$-aminocaproic acid before cardiopulmonary bypass. Ann Thorac Surg 1994;57:1108-12.

12. Angelini GD, Cooper GJ, Lamarra M, Bryan AJ. Unorthodox use of aprotinin to control life-threatening bleeding after cardiopulmonary bypass. Lancet 1990;355:799-800.

13. Kallis P, Tooze JA, Talbot S, Cowans D, Bewan HD, Treasure T. Aprotinin inhibits fibrinolysis, improves platelet adhesion and reduces blood loss: results of a double-blind randomized clinical trial. Eur J Cardiothorac Surg 1994;8: 315-23.

14. Blauhut B, Harringer W, Bettelheim P, Doran JE, Spath P, Hansen PL. Comparison of effects of aprotinin and tranexamic acid on blood loss and related variables after cardiopulmonary bypass. J Thorac Cardiovasc Surg 1994;108:1083-91.

15. Fritz H, Wunderer G. Biochemistry and applications of aprotinin, the kallikrein inhibitor from bovine organs. Arzneimittelforsch 1983;33:479-94.

16. van Oeveren W, Harder MP, Roozendaal KJ, Eijsman L, Wildevuur CRH. Aprotinin protects platelets against the initial effect of cardiopulmonary bypass. J Thorac Cardiovasc Surg 1990;99:788-97.
17. Köstering H, Kirchhof PG, Völker P, Warmann E, Koncz J. Untersuchungen der Blutgerinnungsveranderungen wahrend und nach Operation mit Hilfe der Herz-Lungen-Maschine. Thoraxchirurgie 1973;21:534-43.

18. Royston D, Taylor KM, Bidstrup BP, Sapsford RN. Effect of aprotinin on need for blood transfusion after repeat open heart surgery. Lancet 1987;2:1289-91.

19. Gram J, Janetzko T, Jespersen J, Bruhn HD. Enhanced effective fibrinolysis following the neutralization of heparin in open heart surgery increases the risk of post-surgical bleeding. Thromb Haemost 1990;63:241-5.

20. Valen G, Eriksson B, Risberg B, Vaage J. Fibrinolysis during cardiac surgery: release of tissue plasminogen activator in arterial and coronary sinus blood. Eur $\mathbf{J}$ Cardiothorac Surg 1994;8:324-30.

21. Lucas FV, Miller ML. The fibrinolytic system. Cleve Clin J Med 1988;55:531-41.

22. Michelson AD, Barnard MR. Plasmin-induced redistribution of platelet glycoprotein Ib. Blood 1990;76:2005-10.

23. Zilla P, von Oppell U, Deutsch M. The endothelium: a key to future. J Cardiac Surg 1993;8:32-36.

24. Espana F, Estelles A, Griffin JH, Aznar J, Gilabert J. Aprotinin (Trasylol) is a competitive inhibitor of activated protein C. Thromb Res 1989;56:751-6.

25. Dahlback B. The protein C anticoagulant system: inherited defects as basis for venous thrombosis. Thromb Res 1994;77: $1-43$.

\section{Availability of Journal back issues}

As a service to our subscribers, copies of back issues of The Journal of Thoracic and Cardiovascular Surgery for the preceding 5 years are maintained and are available for purchase from Mosby at a cost of $\$ 15.00$ per issue until inventory is depleted. The following quantity discounts are available: $25 \%$ off on quantities of 12 to 23 , and one third off on quantities of 24 or more. Please write to Mosby-Year Book, Inc., Subscription Services, 11830 Westline Industrial Drive, St. Louis MO 63146-3318, or call 800-453-4351 or 314-453-4351 for information on availability of particular issues. If unavailable from the publisher, photocopies of complete issues may be purchased from UMI, 300 N. Zeeb Rd., Ann Arbor, MI 48106, 313-761-4700. 